Provided for non-commercial research and education use. Not for reproduction, distribution or commercial use.

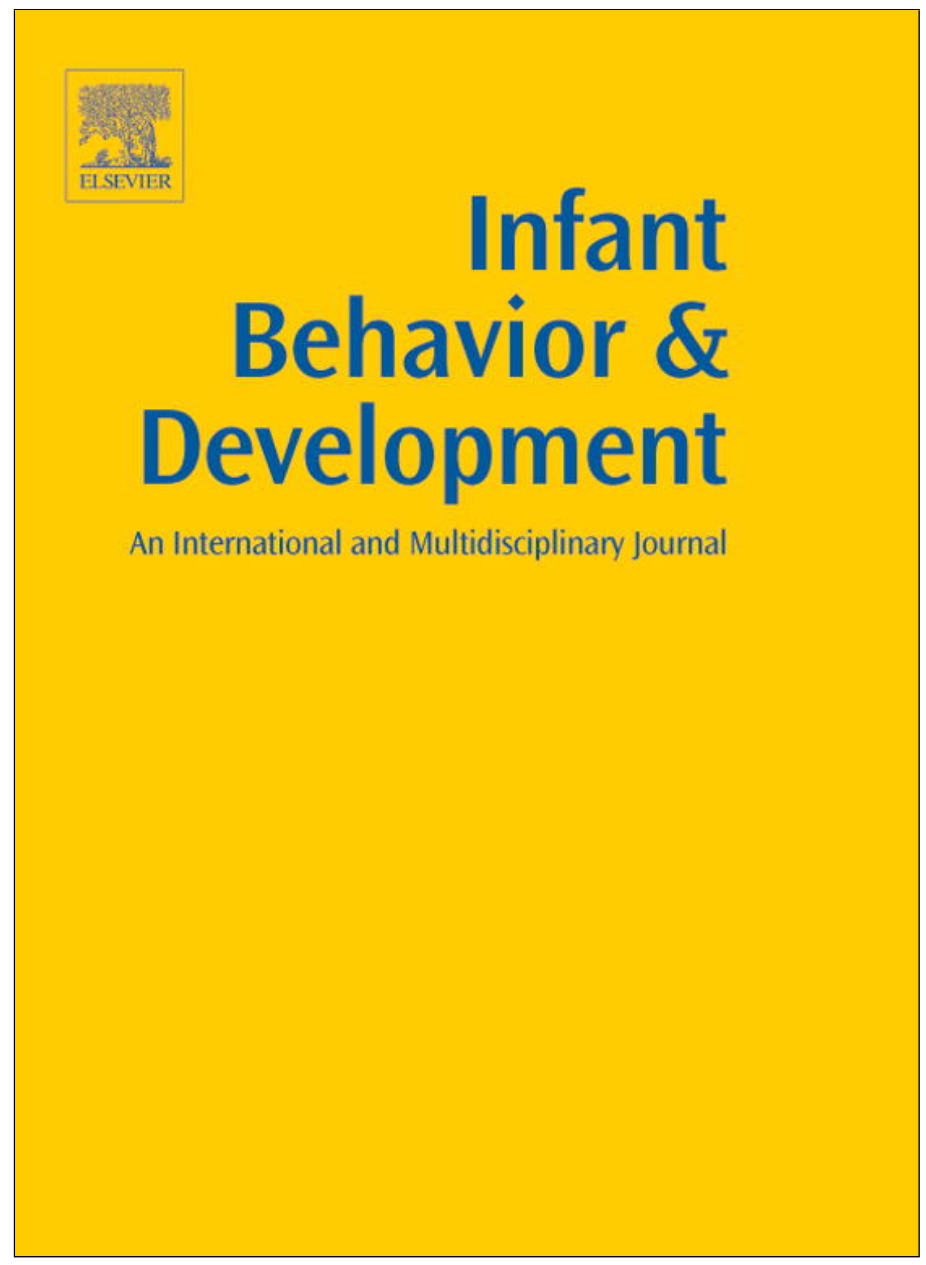

(This is a sample cover image for this issue. The actual cover is not yet available at this time.)

This article appeared in a journal published by Elsevier. The attached copy is furnished to the author for internal non-commercial research and education use, including for instruction at the authors institution and sharing with colleagues.

Other uses, including reproduction and distribution, or selling or licensing copies, or posting to personal, institutional or third party websites are prohibited.

In most cases authors are permitted to post their version of the article (e.g. in Word or Tex form) to their personal website or institutional repository. Authors requiring further information regarding Elsevier's archiving and manuscript policies are encouraged to visit:

http://www.elsevier.com/copyright 


\title{
Do toddlers prefer the primary caregiver or the parent with whom they feel more secure? The role of toddler emotion
}

\author{
Tomo Umemura*, Deborah Jacobvitz, Serena Messina, Nancy Hazen \\ University of Texas at Austin, United States
}

\section{A R T I C L E I N F O}

\section{Article history:}

Received 2 February 2012

Received in revised form 27 July 2012

Accepted 3 October 2012

\section{Keywords:}

Attachment hierarchy

Attachment security

Caregiving

Fathers

Family interaction

\begin{abstract}
A B S T R A C T
This study tested Bowlby and Ainsworth's hypothesis that a hierarchy of caregivers exists whereby infants prefer one caregiver over another when distressed. We examined parent gender (mother vs. father), primary caregiver status (defined as the parent who spent most time with the infant and performed most of the caregiving tasks), and role of toddlers' history of attachment security with each parent, as predictors of toddlers' preference for a particular caregiver when the toddlers are distressed and when they are content. Infants' attachment security with each parent was assessed at 12-15 months. At 24 months, mother-child and father-child interactions were observed in triadic (mother, father, toddler) home interactions. When distressed, regardless of the security of their attachment to each parent, toddlers more often interacted with the primary caregiver. When content, toddlers did not show this preference. As expected, toddlers' recovery from distress was predicted by their security of attachment with the parent whom they approached when distressed.
\end{abstract}

(c) 2012 Elsevier Inc. All rights reserved.

\section{Introduction}

Bowlby (1969/1982) proposed that when children engage in attachment behavior, such as seeking closeness and physical contact, they consistently direct their behaviors to one principal caregiver. The preferred parent is presumed to be the primary caregiver, that is, the parent who is more likely to take responsibility for the child when that child is ill or hurt. Evidence for such preferences, however, has been mixed. Laboratory studies found that when infants and toddlers were distressed as a result of separating from their parent, they more often sought comfort from their mother (who is usually the primary caregiver) rather than their father (Colin, 1985; Cummings, 1980; Lamb, 1976). Yet, this preference has not been found in naturalistic observational studies conducted at home (Belsky, 1979; Clarke-Stewart, 1978; Lamb, 1977a, 1977b). This may be because variations in infants' preferences for a particular caregiver are due to variations in the infants' emotional state (Ainsworth, 1982). That is, infants may prefer the primary caregiver only when their attachment system is activated, that is, when they are feeling tired, ill or distressed. Moreover, since an infant's attachment security is largely a function of the extent to which that parent is able to comfort the distressed infant, infants' security of attachment with a particular parent may predict their preference for that parent. That is, infants who are securely attached with their father, but not their mother, may prefer their father, even though their mother is the primary caregiver. The present study is the first to examine simultaneously the factors contributing to toddlers' preference for one parent over another: parents' gender (mother or

\footnotetext{
* Corresponding author at: University of Texas at Austin, Human Development and Family Sciences, 1 University Station Stop A2702, Austin, TX 78712, United States. Tel.: +1 5124758888

E-mail address: tomoumemura@utexas.edu (T. Umemura).
} 
father), whether or not the parent is the primary caregiver, security of infants' attachment relationship with the parent and toddlers' emotional state (distressed or content).

\subsection{Children's preferences for caregivers}

According to Bowlby's control systems model, children continually monitor their primary caregiver while exploring the environment when they are not distressed. Once distressed, the child immediately and directly comes back to the caregiver to recover in her/his arms. Ainsworth (1982) later elaborated Bowlby's idea, emphasizing that children do direct attachment behaviors toward both primary and subsidiary caregivers, but prefer to engage with their primary caregiver when tired, ill, or distressed. Children are also more distressed when they are separated from their primary caregiver versus other caregivers. Since the extent to which children display attachment behaviors depends on specific caregivers, Ainsworth (1982) called this phenomenon children's hierarchical preference.

Evidence for infants' preference for one primary caregiver has been reported across several cultures with different caregiving arrangements. In Ainsworth's (1967) naturalistic observations in Uganda, babies who were hungry, tired, ill, or alarmed directed most of their attachment behavior toward the mother if she was available. Also, Ainsworth reported that Ganda infants ordinarily cried when their mother left the room, whereas they did not cry when other caregivers departed. Similarly, Morelli and Tronick (1991) found that although Efe infants typically experience caregiving from multiple adults, they seem to prefer their own mothers, who cared for them most frequently (e.g., comforting them at night).

In laboratory research in the United States, infants have typically shown a preference for their mothers (who are usually the primary caregiver) over their fathers (Colin, 1985; Lamb, 1976) and daycare providers (Cummings, 1980; Farran \& Ramey, 1977). For example, Lamb (1976) and Colin (1985) developed experimental situations in which an infant was left alone or with a stranger in a laboratory, and then both parents entered the room. These studies created moderate stress in the infant and an opportunity for the infant to choose between caregivers. Both studies found that infants preferred their mothers following this brief separation. Colin (1985) reported that most 12- to 19-month-old babies approached or showed distal interaction directed toward their mothers over their fathers or their childcare providers, although some babies chose to direct behavior to their fathers or childcare providers rather than to their mother, or showed no clear preference for a particular caregiver. However, Lamb reported that although 12- and 18-month-old infants turned to their mothers preferentially, 8and 21-month-old did not (see the summary of his laboratory observations; Lamb \& Lewis, 2004). Thus, previous laboratory research leaves open the question regarding the extent to which a preference for a specific parent exists, especially during toddlerhood.

Using home observation of triadic interactions, Lamb (1977a, 1977b) initially found that during their second year of life, children more often sought to be held by their father than by their mother. This finding, however, was inconsistent with Lamb's (1976) laboratory studies. Findings from two subsequent studies conducted in the home helped explain these inconsistent results (Belsky, 1979; Clarke-Stewart, 1978). After controlling for parents' initiations of interactions with their children, children's preference for their fathers disappeared. Specifically, the children neither showed things more often to their fathers, rather than to their mothers, nor moved toward fathers more frequently than toward mothers, although children were still more likely to direct their vocalizations to their fathers. Therefore, the present study will take into account who initiates the behavior, toddler versus parent, when examining the toddler's preference for a particular caregiver.

\subsection{The role of emotion in children's preferences}

Drawing on ethological theory, Bowlby (1969/1982) explained that infants' seeking proximity or physical contact with their primary caregiver when he or she is tired, ill, or uncertain about the caregiver's whereabouts is an evolutionary adaptation of the species. Infants' fear of being sick, being in unfamiliar environments, and being separated from their caregivers all stem from anxiety related to survival (Robertson \& Bowlby, 1952; Sroufe \& Waters, 1977). Under these conditions, therefore, infants typically express distress and then display attachment behaviors (e.g., seeking proximity, seeking physical contact, and communicating from a distance to their caregivers) because when they are with their caregivers, their chance of survival increases.

Thus, it is possible that differences in children's emotional state account for the findings demonstrating that toddlers' preference for their mothers versus their fathers differed in the laboratory and home setting. In the laboratory settings (Colin, 1985; Lamb, 1976), children were separated from their parents and therefore likely to be quite distressed. In the home settings (Belsky, 1979; Clarke-Stewart, 1978; Lamb, 1977a, 1977b), in contrast, whether or not children were distressed when they approached the parent was not examined. When infants and toddlers are content, they may seek interaction from either caregiver. Previous studies have found that fathers often engage in physically stimulating and unpredictable play (ClarkeStewart, 1978; Hazen, McFarland, Jacobvitz, \& Boyd-Soisson, 2010; Paquette, 2004; Power \& Parke, 1983; Teti, Bond, \& Gibbs, 1988). For example, fathers tend to provide staccato bursts of both physical and social stimulation to their newborn infants whereas mothers tend to be more rhythmic and containing (Yogman, 1981). In addition, Belsky (1979) found that whereas fathers are more likely to interact with their infant while playing or at their infant's request, mothers have been found to engage in more caregiving responsibilities. However, mothers also play with their children. In Yarrow et al.'s (1984) study, for example, mothers reported spending an average of $17.5 \mathrm{~h}$ at 6 months and $16.4 \mathrm{~h}$ at 12 months playing with their infants, 
while fathers spent an average of $6 \mathrm{~h}$ at 6 months and $7.3 \mathrm{~h}$ at 12 months playing with their infants. Thus, both mothers and fathers play with their infants, which usually occurs when infants express positive emotion.

\subsection{The role of attachment security in triadic family interaction}

Although previous studies have examined children's preferences and have distinguished between characteristics of mother-child and father-child interactions, virtually no study has examined triadic interactions in light of the child's history of attachment security with each parent. A large body of research has demonstrated that there exist individual differences in infants' and toddlers' attachment relationships with their primary caregiver (e.g., see Weinfield, Sroufe, \& Egeland, 1999, for review). When children are distressed, those who are securely attached to their primary caregiver are able to seek help from their caregiver and recover from distress (Sroufe, 1995; Waters \& Cummings, 2000).

But will the distressed child be more likely to go to the primary caregiver (the parent that spends most time with the infant and performs most of the caregiving tasks), or to the parent to whom he or she is securely attached? We will examine two possible competing hypotheses. A strong version of primary caregiver hypothesis would hold if, in a triadic interaction, the child went to the primary caregiver when distressed regardless of that child's secure or insecure history with each parent. In contrast, a strong version of attachment security hypothesis would hold that the distressed child would be more likely to prefer the parent with whom he or she had a secure history than the parent with whom he or she had an insecure history, regardless of the parent's primary (vs. subsidiary) caregiver status.

These competing hypotheses are both consistent with attachment theory. According to Bowlby's (1969/1982) ideas about control systems, children continually calibrate their distance from their primary caregiver and when distressed, they preferentially turn to this person. Given this habitual behavior, even whenever a parent with whom toddlers feel more secure is present, it may be unlikely that they will change the target parent to approach when they are in need. On the other hand, preferring a parent with whom children have a more secure relationship may benefit them because a secure attachment may promote healthy emotional development (Cameron, Ungar, \& Liebenberg, 2007). Given that the role of attachment security in children's preferences has not been explored, a primary goal of the present study is to examine whether toddlers' history of attachment security is associated with their preference at times when they are distressed.

\subsection{Assessing primary caregiver status}

To examine these hypotheses, the child's primary caregiver should be identified. The infants' primary caregiver is defined as the person who is primarily responsible for the infant's care, from the infant's point of view. Since it is not possible to directly assess the infants' point of view, previous empirical studies in the U.S. have assumed that mothers are the primary caregiver and fathers are a subsidiary caregiver (Colin, 1985; Lamb, 1977a, 1977b). This makes sense because mothers in the U.S. take the primary roles in their caregiving involvement. For example, a national random study indicates that $91 \%$ of American mothers are primarily responsible for choosing and offering food to their infants and toddlers (Carruth, Ziegler, Gordon, \& Barr, 2004). Moreover, on average, mothers spend far more time with their children than do fathers. According to Sasaki, Hazen, and Swann (2010), the average number of hours mothers in the present study spent with their 8-month child alone ( $28.7 \mathrm{~h}$ per week) was far longer than the average amount of time fathers spent alone ( $9.7 \mathrm{~h}$ per week).

However, mothers are not always the primary caregiver. Marvin, VanDevender, Iwanaga, LeVine, and LeVine (1977) observed 15 mobile Hausa infants in their natural polymatric settings in Nigeria in which there are multiple women caring for the child. Although the biological mother played a major role in the physical care (e.g., feeding), it is common that in polymatric cultures, only some mothers play a major role in responding to their babies' emotional needs (e.g., comforting). The authors reported that although all 15 infants directed attachment behavior toward more than one caregiver, 14 of the 15 babies showed attachment behavior most frequently to the caregiver who held them and interacted with them the most. Interestingly, in 8 of these 14 cases, the caregiver was not the biological mother. Thus, fathers who spend more time with the infant and/or perform more caregiving tasks may be viewed by the infant as the primary caregiver.

To address this issue, we will consider not only the gender of the parent, but also other indicators of primary caregiver status: the amount of time each parent spends with their toddler, the extent to which each parent performs caregiving tasks, and the combined amount of time and the number of caregiving tasks (termed "cumulative primary caregiver status"). We will then examine the extent to which parent gender and measures of primary caregiver status uniquely predict toddlers' preference for a particular parent.

\subsection{Attachment security and toddlers' recovery from distress}

After approaching a caregiver, a child may receive comfort from the caregiver and recover from distress. The idea that secure children can successfully recover from distress has been confirmed in previous studies (e.g., Diener, Mangelsdorf, McHale, \& Frosch, 2002; Kochanska, 2001). Shaver and Mikulincer (2007) explained that a secure attachment promotes a sense that a caregiver will be available when the child is in need and the world is safe in general. Although these studies were examined in caregiver-child dyadic contexts, it is expected that in triadic contexts, the extent to which a child recovers from distress should be predicted by the child's attachment security with the parent from whom that child sought comfort. 
In sum, the current study will investigate whether 24-month-old toddlers are more likely to prefer a particular parent in the context of triadic (mother, father, and toddler) family interactions at home, both when the toddlers are distressed and when they are in a positive mood. Since it was expected that children would seek a particular caregiver when distressed, we specifically included parent-child and triadic interaction tasks that have been found to induce stress. We will examine the two competing hypotheses. The primary caregiver hypothesis will be supported if distressed toddlers choice for a particular parent is predicted by indices of primary caregiver status (parent gender, time spent with child, the number of caregiving tasks performed, or cumulative primary caregiver status) rather than the parent's attachment history with them. In contrast, the attachment security hypothesis will be supported if distressed toddlers' preference is predicted by the toddlers' attachment security with the parent rather than the parents' primary caregiver status. We also hypothesize that when toddlers are distressed and then seek comfort from a parent, toddlers who have a secure history with that parent will be more likely to recover from distress while interacting with that parent, compared to toddlers who have an insecure history.

\section{Method}

\subsection{Participants}

Participants were part of a longitudinal study investigating family relationships over the transition to parenthood (e.g., Jacobvitz, Hazen, Curran, \& Hitchens, 2004; Jacobvitz, Leon, \& Hazen, 2006). A total of 125 couples were recruited in the Austin area when the wives were in their third trimester of pregnancy expecting their first child. Recruitment was conducted via presentations in birthing classes, public service TV announcements and flyers distributed at maternity stores. All participants were offered a $\$ 50$ savings bond at each of the three phrases $(\$ 50 \times 3=\$ 150$ total). Also, bimonthly project newsletters, a T-shirt for their infant, and an audiotape of lullabies were given to participants.

Data for the present study were collected when the child was 12/15 months and 24-29 months old. At 24-29 months $(M=25.20$ months, $S D=0.94), 97$ parents and their toddlers (38 girls) participated in the triadic interactions. Since the initial recruitment, 11 families had moved away, two families could not be located, three families were too busy to participate and 12 couples were divorced. In addition, one family was excluded from the analysis due to a technical problem (i.e., lack of audio on the videotape).

The distribution of the families' total income varied: $8 \%$ made under $\$ 15,000,12 \% \$ 15,001-\$ 30,000,32 \% \$ 30,001-\$ 45,000$, $25 \% \$ 45,001-\$ 60,000$, and $22 \%$ made over $\$ 60,001$. The mean age of mothers was $29.48, S D=4.73$, and the mean age of fathers was $31.66, S D=6.17$. Ten percent of the mothers and $8 \%$ of the fathers earned a high school degree, $25 \%$ of the mothers and $35 \%$ of the fathers had some training beyond high-school but did not graduate from college, $46 \%$ of the mothers and $38 \%$ of the fathers earned a bachelor degree, and $18 \%$ of the mothers and $18 \%$ of the fathers had a graduate or post-college degree. The racial distribution among mothers in the sample was $83 \%$ Caucasian, 6\% Hispanic, 3\% African American, and 8\% biracial or "other." Among fathers, 87\% were Caucasian, 7\% Hispanic, 4\% African American, and 2\% were biracial or classified themselves as "other." Families who participated in both phases did not differ on any demographic variables from families who dropped out of the study.

\subsection{Procedure}

When infants were 12 and 15 months old, either the mother or father came to a laboratory at the university with the infant to participate in the Strange Situation procedure. The order of mother or father participation was counterbalanced. When the children were 24-29 months old, research assistants visited the family at home to videotape mother, father, and toddler in a series of triadic family interactions tasks lasting approximately $25 \mathrm{~min}$. Both parents also filled out a schedule reporting who cared for the child during every hour of a typical week at 8 and 24 months and completed questionnaires about their own and their partner's involvement in caregiving tasks at 24 months.

\subsection{Attachment security with mother and father}

At 12/15 months, mother-infant and father-infant dyads were videotaped in the Strange Situation procedure (see Ainsworth, Blehar, Waters, \& Wall, 1978, for details) to assess the infant's attachment security with each parent. In this laboratory procedure, an infant is separated from and then reunited with the parent. Based on the infant's behavior during the reunion with the parent, he or she was classified as forming one of four attachment relationships with the parent: secure (B), insecure-avoidant (A), insecure-resistant (C), or disorganized (D). Infants were considered secure if they used their parent as a secure-base, seeking comfort when distressed following brief separation, and then successfully reducing their distress. Infants were categorized as insecure-avoidant if they displayed avoidant behavior during the reunion with their parent, for example, turning away from the parent when the parent returned to the room. Infants were considered insecure-resistant if they showed a mixture of proximity-seeking and anger toward the parent, for example, running to the parent to be picked up and held, and then hitting the parent. Finally, babies were categorized as disorganized if they displayed disoriented behavior, such as entering trance-like states (e.g. freezing), fearful apprehension or other inexplicable behavior in the presence of their caregiver (Main \& Solomon, 1990). 
Infants' attachment classification with their mother and father was coded by four researchers, all of whom were reliable on the standard set of tapes provided by Alan Sroufe and Elizabeth Carlson. All videotapes were coded at least twice. The trainers (Mary Main and Elizabeth Carlson) reduced differences on the disorganized attachment status for 25 difficult cases. The inter-rater reliability on the 4-way classification (A, B, C, D categories) was $k=.74$. Since a primary question of this study is how a history of attachment security (but not different types of insecure categories) influence toddlers' preference for their parents, we used only the two-way classification, secure (B) vs. insecure (A, C, D), in all analyses.

\subsection{Primary caregiver status}

\subsubsection{Hours spent with each parent}

At 8 and 24 months, parents indicated how many hours/week each parent, as well as other caregivers, spent with their toddler. Parents jointly completed a schedule of their infant's typical week by indicating the hours their infant spent each day from 6 a.m. to 11 p.m. with the mother only, the father only, the mother and father together, or in non-parental child care. The index of hours spent with each parent reflected the number of hours per week each parent spent with the infant alone. Because hours spent with each parent was highly stable from 8 to 24 months $(\alpha=.80)$, we averaged the hours at 8 and 24 to obtain a final score for the amount of time each parent spent with the child.

\subsubsection{Caregiving involvement}

Mothers and fathers independently completed a social network questionnaire, adapted from Bost, Cielinski, Newell, and Vaughn (1994), rating how often they and their spouse were involved in six caregiving tasks on 7-point scales (1 = Never; 7 = Everyday). The six tasks included awakens child, dresses child, supervises child at home, bathes child, puts child to bed, and looks after child when sick. The reliability between mothers' and fathers' ratings was moderate to high: awakens child $(\alpha=.79)$, dresses child $(\alpha=.73)$, supervises child at home $(\alpha=.64)$, bathes child $(\alpha=.91)$, puts child to bed ( $\alpha=.82)$, and looks after child when sick $(\alpha=.74)$. Internal consistency of each caregiving tasks was high $(\alpha=.72)$. Thus, we averaged all the caregiving tasks to obtain each parent's caregiving involvement score.

\subsubsection{Cumulative primary caregiver status}

Using both the amount of time spent with the child and caregiving involvement scores, we developed a composite measure of which parent is more likely to be the primary caregiver. Specifically, when one parent spent more time with the child and was more involved in caregiving tasks than the other parent, that parent was assigned as the primary caregiver. The other parent who spent less time with the child and was involved in fewer caregiving tasks was assigned as the secondary caregiver. When one parent spent more time with the child but engaged in fewer caregiving tasks than the other parent, or spent less time but engaged in more caregiving tasks, the parent's primary caregiver status was defined as unclear. Hence, our coding system (the primary caregivers were coded as 1 while caregivers classified as the secondary caregiver or unclear were coded as 0 ) enabled us to understand whether infants were more likely to go to the parent who was clearly the primary caregiver, based on both indices of primary caregiver status.

\subsection{Toddlers' triadic family interactions at home}

\subsubsection{The triadic interaction tasks}

Triadic family interactions (mother, father, and toddler) were videotaped in the family's home for approximately 25 min when the toddler was 2 years old. First, a researcher described the tasks to the parents and requested that the target child stays in the same room with the parents during all of the tasks. The first task involved the parents completing a Q-sort task together. The Q-sort consisted of 20 items related to caregiving selected from the 100-item California Child Q-sort (Block, 1961). Parents were told to place each item into one of 7 piles (most to least characteristic). Each item reflected one of the two parents' attitudes toward childrearing - in this study we alternated between husband and wife. One parent was asked to read the Q-sort item and decide how the target parent would rate the item. Then the other parent was asked to say how he/she would rate the item, and the couple was asked to reach an agreement before placing the item in the pile. The purpose of the Q-sort task was to observe how the parents resolve differences and complete an adult task while still caring for their toddler. The second task required the couple to fix a snack and eat it together with their child. The third task involved changing the child's clothes. These tasks were chosen because they reflect everyday activities that parents and children generally do together, and they may elicit distress from toddlers. If families completed all the tasks in less than $20 \mathrm{~min}$, the family was asked to complete a peg-sorting game for the fourth task. The family was told they could do the task in any order, allowing them to flexibly adjust their behavior to reflect what they usually do at home.

\subsubsection{Toddlers' preference for mother versus father}

To determine toddlers' preference for one parent over the other, we coded the frequency with which each toddler initiated interaction with each parent and the toddler's emotional state when initiating the interaction. This coding system was based on the Family Process Code (Dishion, Gardner, Patterson, Reid \& Thibodeaux, 1983), which examined the child's emotional state, the initiator of the interaction, the recipient of the interaction, and the type of interaction. We coded all of these dimensions except the type of interaction. Coding took place in three steps. First, researchers coded toddlers' emotional states. 
Table 1

Concordance between children's security of attachment to mother and father.

\begin{tabular}{|c|c|c|c|c|c|c|}
\hline \multirow[b]{3}{*}{ Attachment to father } & \multicolumn{4}{|c|}{ Attachment to mother } & & \\
\hline & \multicolumn{2}{|c|}{ Secure } & \multicolumn{2}{|c|}{ Insecure } & \multicolumn{2}{|c|}{ Total } \\
\hline & $n$ & $(\%)$ & $n$ & $(\%)$ & $n$ & $(\%)$ \\
\hline Secure & 37 & (36) & 20 & $(20)$ & 57 & (56) \\
\hline Insecure & 22 & (22) & 23 & $(23)$ & 45 & (44) \\
\hline Total & 59 & $(58)$ & 43 & $(42)$ & 102 & $(100)$ \\
\hline
\end{tabular}

Note: Percentages are rounded to the nearest whole number.

Next, for each emotional state, the initiator and recipient of the interaction was coded. Finally, researchers coded the degree to which the child was comforted by the interaction with the parent. The Observer ${ }^{\circledR} 5.0$ (Noldus Information Technology, 2003) was used allowing us to input multiple coding into one chart.

Toddlers' emotional states. One set of coders first recorded when toddlers began and ended displays of emotion. On the basis of nonverbal gestures, body postures, facial expressions, tone of voice, and quality of play, we coded three categories of emotion: (a) positive emotion, (b) negative emotion (i.e., distress), and (c) neutral emotion. Positive emotion was coded when the target toddler showed an intensive expression of joy, including laughter and quick movements as well as more mild expressions of happiness (e.g., smiling). Negative emotion was coded when the toddler appeared sad, anxious, distressed, cried sadly and/or mildly complained. Neutral emotion was assessed when the toddler expressed neither positive nor negative emotion. Finally, when the target toddler was off screen for more than $10 \mathrm{~s}$, emotions were coded as unobservable (the present study will not include this unobservable category).

Regarding inter-observer agreement, the primary coder and the reliability coder were individually trained by watching videotapes of toddler-parent interactions obtained from a different phase of the study. Each observer coded all of the triadic interactions. The average percentage of agreement between the two coders (i.e., the duration of emotions coded as the same) was $81 \%$.

Initiators and recipients of interactions. Next, a second set of coders recorded who initiated and who was the recipient of the interaction when toddlers expressed positive or negative emotions. Because the purpose of the study is to understand toddlers' preference for a particular parent, we only coded toddler-initiated interactions, not parent-initiated or parent-parent interactions. Hence, toddler-parent interactions that occurred when the child displayed an emotion (whether positive or negative) were classified as (a) toddler-initiated during toddler-motherinteractions or (b) toddler-initiated during toddler-father interactions. For example, toddlers experiencing positive emotion might initiate interaction through physical contact with a parent (e.g., alternating playing with a toy with running over and bumping into the parent), or by interacting at a distance (e.g., talking to or smiling at the parent). When showing negative emotions, toddlers might ask for instrumental help (e.g., one toddler became frustrated, struggling to understand how to use a toy, and asked the parent for help) or seek emotional comfort, such as hugs or cuddling. The second group of coders was also provided with individualized training using videos obtained from a different phase of the study. Both the primary observer and the reliability observer coded $100 \%$ of videotapes, and the average kappa was .71.

Toddlers' recovery from distress. Finally, whenever the toddler was distressed and initiated an interaction with the parent, a third independent set of observers, using a 9-point scale, rated the extent to which the child was able to recover from the distress. A score of 9 was given when the child appeared to recover completely as a result of interacting with the parent, showed positive emotions (e.g., smiles, positive affective voice tone, exuberance), and re-engaged in play. Lower scores (rating $=2$ ) were given when the child showed anger (e.g. moving away from the parent with an angry expression), took a long time to recover, or initiated but did not actively maintain interaction. The lowest rating of 1 was assigned to parent-child interactions that escalated the child's distress. Regarding inter-coder agreement, the correlation coefficient between these two coders' scores was .74. The average rating of the two coders was used for the analyses when the difference between the scores was within 2 points. For the five cases in which disagreement was more than 2 points, the coders discussed their scores and generated a final agreement rating.

\section{Results}

\subsection{Descriptive statistics}

\subsubsection{Attachment classifications with the mother and father in infancy}

Descriptive data pertaining to the child's attachment relationship with mother and father during infancy is presented in Table 1. The percentage of infants classified as secure versus insecure was almost identical for mothers (58\% secure; $42 \%$ insecure) and fathers (56\% secure; $44 \%$ insecure). A chi-square analysis showed no statistically significant concordance between infant-mother and infant-father attachment classifications, $\chi^{2}(1, N=102)=2.03, p=.15$, n.s. Specifically, $57 \%$ of the infants had the same classifications with their mother and father, while $43 \%$ of the infants had different classifications with their mother and father. 
Table 2

Correlations among indicators of primary caregiver status (i.e., parent's gender, time spent with toddler, caregiving involvement, and cumulative primary caregiver status) and attachment security.

\begin{tabular}{|c|c|c|c|c|c|}
\hline & 1 & 2 & 3 & 4 & 5 \\
\hline 1. Parent's gender $($ mother $=1 /$ father $=0)$ & - & $.68^{* * *}$ & $.52^{* * *}$ & $.56^{* * *}$ & .02 \\
\hline 2. Time spent with toddler & & - & $.57^{* * *}$ & $.58^{* * *}$ & -.05 \\
\hline 3. Caregiving involvement & & & - & $.60^{* * *}$ & .01 \\
\hline 4. Cumulative primary caregiver status ( primary $=1 /$ secondary or unclear $=0$ ) & & & & - & -.04 \\
\hline 5. Attachment security $($ secure $=1 /$ insecure $=0$ ) & & & & & - \\
\hline
\end{tabular}

Table 3

Bivariate relations of frequency of toddler-initiated interactions when showing negative and positive emotions with duration of toddlers' emotion.

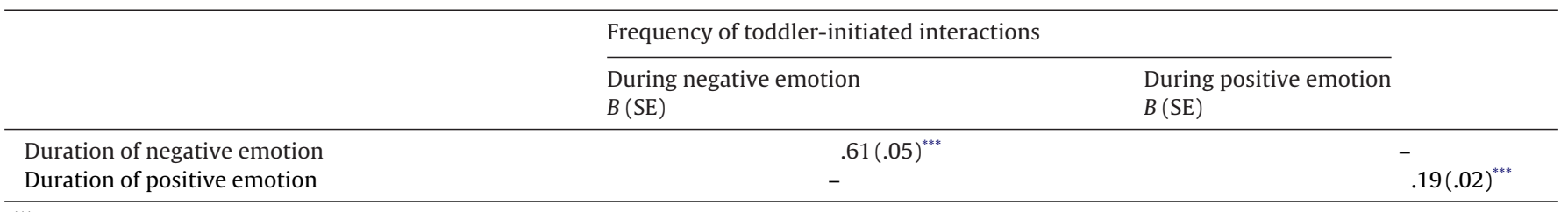

*** $p<.001$.

\subsubsection{Parent gender and measures of primary caregiver status}

Mothers spent significantly more time with toddlers $(M=37.54 \mathrm{~h}, S D=21.84)$, than did fathers $(M=7.86 \mathrm{~h}, S D=7.31)$, $t(d f=114.81)=12.56, p<.001$. Only eight fathers spent more time with their toddlers than did their wives. Similarly, mothers received significantly higher ratings for involvement in caregiving tasks $(M=5.10, S D=.59)$ compared to fathers $(M=4.21$, $S D=.84), t(d f=164.59)=8.36, p<001$, although 12 fathers had higher ratings for involvement in caregiving tasks than did mothers. Finally, according to our definition of the cumulative primary caregiver status, 77 mothers and two fathers were the primary caregivers, and 20 couples were classified in the unclear category (i.e., either spent more time or involved in more caregiving tasks but not the other). Since there were only two fathers who were the primary caregivers and only one of these fathers completed the Strange Situation, we excluded these two families from the analyses. The one family in which the father was clearly the primary caregiver, and in which both parents completed the Strange Situation, will be discussed descriptively.

\subsubsection{Toddler-parent interactions when the toddler was distressed versus content}

During the triadic interactions, nearly all of the toddlers $(N=90)$ expressed negative emotion at some time $(M=39.74 \mathrm{~s}$, $S D=49.78 \mathrm{~s}$ ), and, on average, infants initiated 2.52 interactions with their parents when distressed $(S D=3.61)$. All 96 toddlers expressed positive emotion $(M=66.12 \mathrm{~s}, S D=69.12 \mathrm{~s})$, and, on average, toddlers initiated 4.52 interactions when content $(S D=3.96)$.

Because the distributions of the triadic interactions were both positively skewed, we used a Poisson regression method, which assumes a skewed distribution (Nussbaum, Elsadat, \& Khago, 2008), for the following analyses. Because the distribution of count data is typically positively skewed (Agresti, 1996/2007; Garson, 2011), this analytical method is appropriate for analyzing count data. At the end of the results section, we also conducted model fit analyses to assess whether the Poisson regression method explained the data better than a regression method that assumes a normal distribution.

\subsection{Bivariate relations among variables}

Correlations among parent's gender, parent's time spent with their toddler, parent's caregiving involvement, parent's cumulative primary caregiver status, and infant-parent attachment classifications are presented in Table 2. As expected, the four indicators of primary caregiver status (parent's gender, time spent with their toddler, caregiving involvement, and cumulative primary caregiver status) were strongly positively correlated. However, they were not related to attachment security.

Bivariate associations among the frequency of toddler-parent interactions and the duration of toddlers' emotional expressions in the triadic contexts are presented in Table 3. As discussed above, the associations were analyzed using Poisson regressions. The longer toddlers expressed negative emotions, the more interactions they initiated, Wald $\chi^{2}(1)=127.51$, $p<.001$. Similarly, the longer toddlers expressed positive emotion, the more interactions they initiated, Wald $\chi^{2}(1)=101.81$, $p<.001$. To minimize individual differences in parents' and toddlers' propensity to initiate interactions with one another, we controlled for the duration of negative/positive emotions and used within-subject designs in the following analyses comparing toddler's preference for a particular parent (see Garson, 2011 for a within-subject design of Poisson regression). Another reason for using a within-subject design is to enable us to compare children's preference for one parent over the other within each family. 
Bivariate relations of toddler-parent interactions and duration of toddlers' emotion with indicators of primary caregiver status and attachment security.

\begin{tabular}{|c|c|c|c|c|}
\hline & \multicolumn{2}{|l|}{ During negative emotion } & \multicolumn{2}{|c|}{ During positive emotion } \\
\hline & Frequency of interactions & Duration of emotion & $\begin{array}{l}\text { Frequency of } \\
\text { interactions }\end{array}$ & $\begin{array}{l}\text { Duration of } \\
\text { emotion }\end{array}$ \\
\hline & $B(\mathrm{SE})$ & $r$ & $B(\mathrm{SE})$ & $r$ \\
\hline $\begin{array}{l}\text { Parent's gender } \\
\qquad(\text { mother }=1 / \text { father }=0)\end{array}$ & $.59(.13)^{* * *}$ & -.02 & $.00(.07)$ & .00 \\
\hline Time spent with toddler & $.06(.03)^{*}$ & -.01 & $-.02(.17)$ & -.01 \\
\hline Caregiving involvement & $.05(.09)$ & -.02 & $-.09(.04)^{*}$ & -.11 \\
\hline $\begin{array}{l}\text { Cumulative primary caregiver } \\
\text { status (primary }=1 / \text { secondary or } \\
\text { unclear }=0 \text { ) }\end{array}$ & $.42(.19)^{*}$ & .05 & $-1.05(.69)$ & -.10 \\
\hline $\begin{array}{l}\text { Attachment security } \\
\quad(\text { secure }=1 / \text { insecure }=0)\end{array}$ & $-.08(.13)$ & -.07 & $.14(.07)^{*}$ & .01 \\
\hline
\end{tabular}

Table 5

Poisson analyses regressing toddler-initiated interactions with parents when toddlers express negative emotion.

\begin{tabular}{|c|c|c|c|c|c|c|c|c|}
\hline & \multicolumn{8}{|c|}{ Toddler-initiated interactions during negative emotion } \\
\hline & \multicolumn{2}{|c|}{ Model 1} & \multicolumn{2}{|c|}{ Model 2} & \multicolumn{2}{|c|}{ Model 3} & \multicolumn{2}{|l|}{ Model 4} \\
\hline & $B$ & (SE) & $B$ & (SE) & $B$ & (SE) & $B$ & $(\mathrm{SE})$ \\
\hline Intercept & -.38 & $(.34)$ & -.55 & $(.27)$ & -.20 & $(.83)$ & -1.20 & $(.31)$ \\
\hline Duration of negative emotion & $.54^{* * *}$ & $(.15)$ & $.55^{* * *}$ & $(.14)$ & $.53^{* * *}$ & $(.15)$ & $.65^{* * *}$ & $(.10)$ \\
\hline Parent's gender & $.59^{* *}$ & $(.19)$ & $.68^{* *}$ & $(.25)$ & $.66^{* *}$ & $(.27)$ & $.64^{* * *}$ & $(.18)$ \\
\hline Time spent with toddler & & & -.02 & $(.05)$ & & & & \\
\hline Caregiving involvement & & & & & -.06 & $(.17)$ & & \\
\hline Cumulative primary caregiver status & & & & & & & $.77^{* *}$ & $(.26)$ \\
\hline Attachment security & -.15 & $(.23)$ & .02 & $(.21)$ & -.14 & $(.27)$ & -.18 & $(.21)$ \\
\hline
\end{tabular}

** $p<.010$

*** $p<.001$

Bivariate associations of the frequency of toddler-parent interactions and the duration of toddlers' emotion during the triadic interaction were also examined in relation to the four indicators of primary caregiver status and attachment security (see Table 4). When toddlers were distressed, toddler-initiated interaction was related to parent's gender, Wald $\chi^{2}(1)=18.02$, $p<.001$, time parent spent with their toddler, Wald $\chi^{2}(1)=3.62, p=.048$, and cumulative primary caregiver status, Wald $\chi^{2}$ $(1)=4.96, p=.026$, but not to ratings of parent involvement in caregiving tasks, Wald $\chi^{2}(1)=.37, p=.542$, n.s., or attachment security, Wald $\chi^{2}(1)=.33, p=564$, n.s. The duration of negative emotion was not related to any indicators of primary caregiver status or to attachment security. When toddlers expressed positive emotion, toddler-initiated interaction was associated with attachment security, Wald $\chi^{2}(1)=3.77, p=.047$, but not with parent's gender, Wald $\chi^{2}(1)=.37, p=.542, n . s$., time parent spent with the toddler, Wald $\chi^{2}(1)=1.77, p=.184$, n.s., or cumulative primary caregiver status, Wald $\chi^{2}(1)=2.28, p=.131$, n.s. Unexpectedly, toddler-initiated interaction was negatively associated with ratings of parent involvement in caregiving tasks, Wald $\chi^{2}(1)=4.60, p=.032$. Like the duration of toddler's negative emotion, the duration of positive emotion was not related to any indicators of primary caregiver status or attachment security.

\subsection{The relation of primary caregiver status and attachment security to toddlers' preferences when distressed}

To determine the extent to which each parent's primary caregiver status and attachment security with the child influence the child's preference for a particular parent when the child is distressed, we performed four multiple regression analyses (see Table 5). In each regression, we set toddler-initiated interactions while showing negative emotions as the dependent variable, and we sequentially controlled for the duration of toddler's negative emotions. In addition, to minimize the likelihood of Type I error resulting from conducting four regressions, we used a standard Bonferroni correction and considered $p<.05 / 4=.013$ to be statistically significant.

In the first regression (Model 1), we entered parent gender (which has been used in most previous studies as a proxy for primary caregiver status) and parent-child attachment security as predictors of the toddler's initiation of interaction with that parent. Results indicated that when distressed, toddlers preferred their mother over their father, independent of attachment security to either parent, Wald $\chi^{2}(1)=8.09, p=.004$. The next three regressions examined parent gender, primary caregiver status, and attachment security as predictors of toddler initiations. This was done to examine the unique contributions of parent gender and primary caregiver status, which are highly correlated, to predicting toddlers' preferences for a particular parent. In Model 2, the measure of primary caregiver status was time parent spent with the child; in Model 3, 
Table 6

Poisson analyses regressing toddler-initiated interactions with parents when toddlers express positive emotion.

\begin{tabular}{|c|c|c|c|c|c|c|c|c|}
\hline \multirow[b]{3}{*}{ Variables } & \multicolumn{8}{|c|}{ Toddler-initiated interactions during positive emotion } \\
\hline & \multicolumn{2}{|c|}{ Model 5} & \multicolumn{2}{|c|}{ Model 6} & \multicolumn{2}{|c|}{ Model 7} & \multicolumn{2}{|c|}{ Model 8} \\
\hline & $B$ & (SE) & $B$ & $(\mathrm{SE})$ & $B$ & $(\mathrm{SE})$ & $B$ & (SE) \\
\hline Intercept & 1.26 & $(.13)$ & 1.29 & $(.14)$ & 1.44 & $(.35)$ & -.06 & $(.26)$ \\
\hline Duration of positive emotion & $.18^{* * *}$ & $(.03)$ & $.19^{* * *}$ & $(.03)$ & $.17^{* * *}$ & $(.03)$ & $.25^{* * *}$ & $(.03)$ \\
\hline Parent's gender & -.03 & $(.02)$ & .09 & $(.11)$ & .01 & $(.07)$ & .29 & $(.19)$ \\
\hline Time spent with toddler & & & -.04 & $(.04)$ & & & & \\
\hline Cumulative primary caregiver status & & & & & & & -.47 & $(.26)$ \\
\hline Attachment security & .10 & $(.12)$ & .11 & $(.13)$ & .10 & $(.14)$ & .02 & $(.19)$ \\
\hline
\end{tabular}

*** $p<.001$.

it was ratings of involvement in caregiving tasks, and in Model 4, it was the cumulative primary caregiver status ( $1=$ Primary caregiver; $0=$ Secondary caregiver or caregiver status unclear).

Parent gender remained a significant predictor of toddler initiations in each of these models, but after controlling for the effects of parent gender, toddler initiations were not predicted by amount of time the parent spent with the child, Wald $\chi^{2}(1)=.21, p=.649$ (see Model 2), or parent involvement in caregiving tasks, Wald $\chi^{2}(1)=.12, p=.725$, $n . s$. (see Model 3). However, the cumulative primary caregiver status was significantly associated with the toddler's preference independent of parent gender and attachment security, Wald $\chi^{2}(1)=8.76, p=.003$ (see Model 4). Attachment security did not predict the child's approach to the parent in any of the models. Thus, toddlers' preference for a particular parent when distressed was uniquely predicted by both the parent's gender and cumulative primary caregiver status, but not by the child's attachment history with that parent. Toddlers were more likely to go to their mothers and to their primary caregivers when distressed, regardless of their attachment security to that parent, supporting the primary caregiver hypothesis.

\subsection{The relation of primary caregiver status and attachment security to toddlers' preferences when content}

The same set of four multiple regression analyses described above was also used to identify the parental characteristics that influenced toddlers' approach when toddlers were content (see Table 6). In this set of regressions, the dependent variable was toddler-initiated interactions while showing positive emotions, and we sequentially controlled for the duration of toddler's positive emotions. To minimize Type I error, we again used a standard Bonferroni correction and considered $p<.05 / 4=.013$ to be statistically significant.

As expected, none of the indicators of primary caregiver status were related to toddler-initiated interactions while toddlers were content. Unlike the bivariate analysis conducted earlier, the history of the child's attachment security to that parent was also not associated with toddler-initiated interaction.

\subsubsection{Goodness-of-model fit}

Finally, to examine how well the Poisson regression models explained the positively skewed count data in the present study, we conducted model fit analyses. The model fits were computed using Quasi Likelihood under Independence Model Criterion (QIC) and Corrected Quasi Likelihood under Independence Model Criterion (QICC), which takes into account the complexity of models (e.g., penalizing a larger number of independent variables). A smaller value of QIC and QICC indicates a better fitting model.

The model fit values for the Poisson analyses presented in Tables 5 and 6 were from QIC $=275.65 / \mathrm{QICC}=265.04$ for the model when toddlers were distressed in which cumulative primary caregiver status was included (i.e., Model 4 , Table 5 ) to $\mathrm{QIC}=548.97 / \mathrm{QICC}=535.02$ for the model when toddlers were content and in which parent's gender was included (Model 5, Table 6). Next, we assessed the models assuming that a dependent variable had a normal distribution, which could also be used for analyzing count data. The model fit values of normal models were all higher than the same models with a Poisson distribution, such as from QIC $=489.21 / \mathrm{QICC}=471.29$ for Model 4 to $\mathrm{QIC}=2519.02 / \mathrm{QICC}=2424.87$ for Model 5 . This indicates that using Poisson regression analyses was effective for examining the positively skewed count data in the present study.

\subsection{The effect of attachment security in infancy on toddlers' recovery from distress}

When toddlers were distressed, attachment security was not found to be related to the preference for one parent over the other. However, we predicted that attachment security would be related to the quality of the child's recovery from distress. For example, whereas an child with an insecure attachment to a parent might go to that parent and keep whining, a child with a secure attachment to a parent might be more likely to obtain comfort from distress, and, thus, engage with that parent positively. To examine this hypothesis, a t-test was conducted with child's attachment security with the approached parent as the predictor variable and the quality of their recovery from distress as the outcome variable. Toddlers who initiated interaction with either their mother or father when distressed were included in this analysis. The quality of toddlers' recovery 


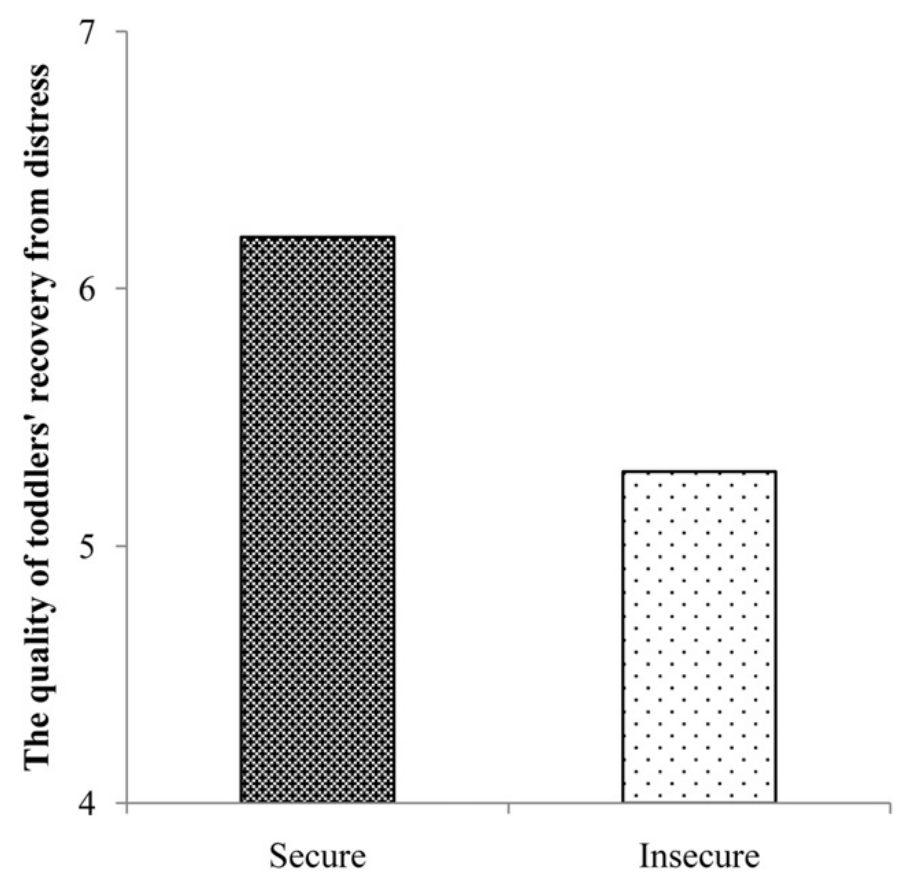

Fig. 1. Toddlers' recovery from distress was predicted by their security of attachment with the parent whom they approached when distressed.

from distress was significantly higher for those who had a secure history with the parent $(M=6.20 ; S D=1.95)$, compared to toddlers who had an insecure history $(M=5.29 ; S D=2.22), F(d f=1,88)=4.17, p=.044$ (see Fig. 1 ). It was also significant even after controlling for the duration of toddlers' negative emotion, $F(d f=1,87)=4.16, p=.044$.

\section{Discussion}

The present study is the first to examine the role of children's emotional state (i.e., distressed versus content), in predicting the extent to which children prefer a particular parent based on that parents' gender, primary caregiver status, and attachment history with the child. We found that when distressed, toddlers preferred to interact with their primary caregivers, regardless of their attachment history with their caregivers. That is, they preferred their mothers over their fathers, and their primary caregiver (that is, the parent who spent more time with them and had greater involvement in caregiving tasks) over the other parent. Although attachment history did not predict toddlers' preference, toddlers who were securely attached to the caregiver they approached were more effective in using that caregiver to recover from distress. In contrast, when toddlers were content, they did not display a preference for either caregiver.

\subsection{The role of toddlers' emotion in their preference}

In contrast to previous studies with 2 year olds (Belsky, 1979; Clarke-Stewart, 1978; Lamb, 1977a, 1977b), the present study provided empirical evidence that toddlers prefer their mother over their father when they are at home, but only when they are distressed. Unlike previous studies, children in the present studies were observed during tasks that induced mild stress, allowing us to examine the role of children's emotional state (distress vs. positive mood).

The present study also examined the effect of the amount of time each parents spent with the toddler and each parents' involvement in caregiving activities as indicators of primary caregiver status. Although mothers in the United States are usually primary caregivers (Carruth et al., 2004) and, thus, previous studies (e.g., Belsky, 1979; Clarke-Stewart, 1978) have considered mothers the primary caregivers, any caregiver can be the primary caregiver if they spend more time with the child and are more involved in caregiving activities (Marvin et al., 1977). The present study also revealed that the combination of the parent's greater time spent with the child and greater involvement in caregiving tasks (e.g., awaking child, dressing child, supervising child at home, bathing child, putting child to bed, and looking after child when sick) predicted the child's preference for that parent even after controlling for parent gender.

\subsection{Preference for the primary caregiver}

The results of this study further confirmed the hypothesis that toddlers prefer their primary caregiver. Drawing on ethological theory, children's preference for the primary caregiver may have evolved because it enhanced the child's survival from predators (Bowlby, 1969/1982). Children may prefer the caregiver who has been more physically available to them and who has usually been responsible for their care. However, each index of primary caregiver status, considered separately (i.e., 
the amount of time spent with the toddler and involvement in caregiving tasks) did not predict the child's preference after controlling for parent gender. This finding suggests that both amount of time spent with the child and amount of caregiving tasks performed should be considered in determining which parent is the primary caregiver. In our sample, since the two mothers who were not the primary caregiver (based on the cumulative criteria) were dropped from the analysis, mothers who were clearly the primary caregiver were compared with those whose primary caregiver status was uncertain (that is, they were higher than fathers on only one of the two criteria). The fact that cumulative primary caregiver status predicted toddlers' preference even after controlling for parent gender indicates that distressed infants were more likely to initiate interaction with mothers who were clearly the primary caregivers than with those whose primary caregiver status was uncertain.

Consistent with our hypothesis, toddlers did not prefer their primary caregiver when content. The fact that toddlers preferred their primary caregiver when distressed but not when they were in a positive mood supports Bowlby's (1969/1982) idea that toddlers prefer to approach the primary caregiver to increase their chance of survival.

\subsection{The influence of attachment history on toddlers' interaction with their parents}

Although the toddler's history of attachment security with a parent did not predict toddlers' preference for that parent when distressed, it did predict the extent to which toddlers recover from distress after seeking interaction from a parent. As expected, toddlers who had a secure history with the parent were comforted and then returned to playing and displaying positive emotion more quickly than did toddlers who had an insecure history with the parent. Hence, the present study revealed that toddlers tend to seek interaction from the primary caregiver but, if they have a secure relationship with the parent they approach for comfort, they are likely to more quickly recover from distress and return to expressing positive emotion.

Our bivariate analysis further revealed that when expressing positive emotion, secure toddlers were more likely than insecure toddlers to interact with their parents. Bowlby (1969/1982) proposed that children go to or look at the mother to check her availability from time to time, suggesting that children still show attachment behavior with a particular caregiver even when they are not distressed. Based on this idea, the Attachment Q-Sort (Waters \& Deane, 1985), which is used to assess individual differences in attachment behavior at home, includes the item, "Child keeps track of mother's location when he plays around the house." Consistent with this idea, studies have shown that even when secure children are not distressed, they are more likely to engage in positive interactions with their mother due to their harmonious relationship. For example, Waters, Wippman, and Sroufe (1979) have shown that 95\% of the secure children displayed a smile directed toward their mother whereas only $45 \%$ of the insecure children smiled during the 3-min observation in the first episode of the Strange Situation procedure. In addition, $21 \%$ of the secure children smiled and/or vocalized when they showed their toys to their mother whereas no insecure children did. Hence, children who have a secure history with their mother should be more likely than children who were insecure in infancy to share positive affect with their mothers.

Finding that toddlers did not prefer parents with whom they were securely attached does not lessen the importance of attachment but rather highlights the importance of attachment-based interventions, which have been a growing area of interest recently (e.g., Dozier, 2003; Marvin, Cooper, Hoffman, \& Powell, 2002). Because children prefer to seek comfort from their primary caregiver regardless of the presence of other caregivers, it is important to guide the primary caregiver as to how to sensitively meet their children's needs. The finding that children were able to recover from distress and obtain comfort more effectively when they approached caregivers with whom they had a secure relationships further highlights the importance of helping parents acquire the caregiving skills that foster attachment security.

\subsection{Conclusions and future directions}

In summary, Bowlby (1969/1982) believed that toddlers prefer the primary caregiver over other caregivers when distressed, and Ainsworth's work (e.g., Ainsworth et al., 1978) suggests that caregivers' capacity to comfort their toddlers is related to the toddlers' attachment security. This study supported both ideas: When distressed, toddlers prefer their primary caregiver independent of their attachment security with that caregiver and independent of parent gender. A history of secure attachment with that caregiver in infancy, however, predicted the effectiveness with which these exchanges help them recover from distress.

Although the present study clearly demonstrated that primary caregiver status is a much stronger predictor of distressed toddlers' preference for a particular parent than is toddlers' attachment history with that parent, it is still unclear how babies decide who their primary caregiver is. In this sample, as in most samples of two-parent middle SES heterosexual households in which fathers are the primary breadwinners, mothers were far more likely than fathers to spend more time with child and to be more involved in caregiving tasks. We found that parent gender and cumulative primary caregiver status both uniquely predict toddlers' preferences. This suggests that babies may be biologically predisposed to prefer the female parent, since females were the primary caregivers during human evolutionary history, but that they may also be predisposed learn who is most responsible for their care through early experiences with their caregivers.

If this is true, what happens when fathers are consistently the primary caregivers? Will infants still prefer their mother, or will they come to prefer their father if he is the parent who clearly and consistently provides more caregiving? Only one father with complete data in our sample was clearly the primary caregiver, based on our cumulative primary caregiver status 
criteria. In this particular family, although the toddler had a secure history with the father and the father was the primary caregiver, the child still initiated more interactions with the mother when he was distressed, even though the child had an insecure attachment to the mother. Although this case supports the possibility that infants may be biologically predisposed to prefer the mother, no conclusions can be drawn on the basis of data from one subject. Thus, to test whether children prefer mothers even when the father is the primary caregiver, or when parents divide child care responsibilities completely equally, it will be important to replicate this study with samples of children living in more diverse family environments, such as with stay-at-home fathers, gay or lesbian parents, and divorced families with joint custody of the child or in which the father is the custodial parent.

Finally, it is important to examine the stability of young children's hierarchical preferences. Children's preferences might change if their parents separate and the child were to live primarily with the secondary caregiver or the grandparents intervene to raise the child. There might also be a critical age period in which children are more or less likely to modify their preference for a particular caregiver. Future research examining the conditions under which children's hierarchical preferences persist could deepen our understanding of the way children organize their attachment behavior.

\section{Acknowledgements}

This research was supported by the National Science Foundation and the Hogg Foundation for Mental Health.

\section{References}

Agresti, A. (2007). An introduction to categorical data analysis (2nd ed.). New York: Wiley. (original work published 1996).

Ainsworth, M. D. S. (1967). Infancy in Uganda: Infant care and the growth of love. Baltimore, MD: Johns Hopkins Press.

Ainsworth, M. D. S. (1982). Attachment: Retrospect and prospect. In J. Stevenson-Hinde, \& C. M. Parks (Eds.), The place of attachment in human behavior. New York: Basic Books.

Ainsworth, M. D. S., Blehar, M., Waters, E., \& Wall, S. (1978). Patterns of attachment: A psychological study of the Strange Situation. Hillsdale, NJ: Erlbaum.

Belsky, J. (1979). Mother-father-infant interaction: A naturalistic observational study. Developmental Psychology: 15., 601-607. http://dx.doi.org/10.1037/0012-1649.15.6.601

Block, J. (1961). The Q-sort method in personality assessment and psychiatric research. Spring-field, IL: Thomas.

Bost, K. K., Cielinski, K. L., Newell, W. H., \& Vaughn, B. E. (1994). Social networks of children attending head start from the perspective of the child. Early Childhood Research Quarterly: 9., 441-462. http://dx.doi.org/10.1016/0885-2006(94)90019-1

Bowlby, J. (1982). Attachment and loss: Vol. 1. Attachment (2nd ed.). New York, NY: Basic Books. (original work published 1969).

Cameron, C. A., Ungar, M., \& Liebenberg, L. (2007). Cultural understandings of resilience: Roots for wings in the development of affective resources for resilience. Child and Adolescent Psychiatric Clinics of North America: 16., 285-330. http://dx.doi.org/10.1016/j.chc.2006.11.001

Carruth, B. R., Ziegler, P. J., Gordon, A., \& Barr, S. I. (2004). Prevalence of picky eaters among infants and toddlers and their caregivers' decisions about offering a new food. Journal of the American Dietetic Association: 104., (Suppl. 1), S57-S64. http://dx.doi.org/10.1016/j.jada.2003.10.024

Clarke-Stewart, K. A. (1978). And daddy makes three: The father's impact on mother and young child. Child Development: 49., 466-478. http://dx.doi.org/10.2307/1128712

Colin, V. (1985). Hierarchies and patterns of infants' attachments to parents and day caregivers: An exploration. Unpublished doctoral dissertation. Charlottesville: University of Virginia.

Cummings, E. M. (1980). Caregiver stability and attachment in infant day care. Developmental Psychology: 16., 31-37. http://dx.doi.org/10.1037/0012-1649.16.1.31

Diener, M. L., Mengelsdorf, S. C., McHale, J. L., \& Frosch, C. A. (2002). Infants' behavioral strategies for emotion regulation with fathers and mothers: Associations with emotional expressions and attachment quality. Infancy: 3., 153-174. http://dx.doi.org/10.1207/S15327078IN0302_3

Dishion, T. J., Gardner, K., Patterson, G. R., Reid, J. B., \& Thibodeaux, S. (1983). The Family Process Code: A multidimensional system for observing family interaction. Unpublished coding manual. Oregon Social Learning Center.

Dozier, M. (2003). Attachment-based treatment for vulnerable children. Attachment and Human Development: 5., $253-325$. http://dx.doi.org/10.1080/14616730310001596151

Farran, D. C., \& Ramey, C. T. (1977). Infant day care and attachment behavior towards mothers and teachers. Child Development: 48., 112-116. http://dx.doi.org/10.2307/1128371

Garson, G. D. (2011). Generalized Linear Models and Generalized Estimating Equations, from Statnotes: Topics in multivariate analysis. Retrieved from http://faculty.chass.ncsu.edu/garson/pa765/statnote.htm

Hazen, N. L., McFarland, L., Jacobvitz, D., \& Boyd-Soisson, E. (2010). Fathers' frightening behaviours and sensitivity with infants: Relations with fathers' attachment representations, father-infant attachment, and children's later outcomes. Early Child Development and Care: 180. ., 51-69. http://dx.doi.org/10.1080/03004430903414703

Jacobvitz, D., Hazen, N., Curran, M., \& Hitchens, K. (2004). Observations of early triadic family interactions: Boundary disturbances in the family predict depressive, anxious, and attention-deficit/hyperactivity disorder symptoms in middle childhood. Development and Psychopathology: $16 ., 577-592$. http://dx.doi.org/10.1017/S0954579404004675

Jacobvitz, D., Leon, K., \& Hazen, N. (2006). Does expectant mother's unresolved trauma predict frightened/frightening maternal behavior? Risk and protective factors. Development and Psychopathology: 18., 363-379. http://dx.doi.org/10.1017/S0954579406060196

Kochanska, G. (2001). Emotional development in children with different attachment histories: The first three years. Child Development: 72., 474-490. http://dx.doi.org/10.1111/1467-8624.00291

Lamb, M. E. (1976). Effects of stress and cohort on mother- and father-infant interaction. Developmental Psychology: 12., 435-443. http://dx.doi.org/10.1037/0012-1649.12.5.435

Lamb, M. E. (1977a). The development of infant-mother and father-infant attachments in the second year of life. Developmental Psychology: 13., 537-578. http://dx.doi.org/10.1037/0012-1649.13.6.637

Lamb, M. E. (1977b). Father-infant and mother-infant interaction in the first year of life. Child Development: 78., 157-181. http://dx.doi.org/10.2307/1128896

Lamb, M. E., \& Lewis, C. (2004). The development and significance of father-child relationships in two-parent families. In M. E. Lamb (Ed.), The role of the father in child development (4th ed., pp. 272-306). Hoboken, NJ: Wiley.

Main, M., \& Solomon, J. (1990). Procedures for identifying infants as disorganized/disoriented during the Ainsworth Strange Situation. In M. Greenberg, D. Cicchetti, \& E. M. Cummings (Eds.), Attachment in the preschool years: Theory, research and intervention (pp. 121-160). Chicago: University of Chicago Press.

Marvin, R. S., Cooper, G., Hoffman, K., \& Powell, B. (2002). The Circle of Security project: Attachment-based intervention with caregiver-preschool child dyads. Attachment \& Human Development: 4., 107-124. http://dx.doi.org/10.1080/14616730252982491 
Marvin, R. S., Vandevender, T. L., Iwanaga, M. I., LeVine, S., \& Levine, R. A. (1977). Infant-caregiver attachment among the Hausa of Nigeria. In H. M. McGurk (Ed.), Ecological factors in human development (pp. 247-260). Amsterdam: North Holland Publishing.

Morelli, G. A., \& Tronick, E. Z. (1991). Efe multiple caretaking and attachment. In J. L. Gewirtz, \& W. M. Kurtines (Eds.), Intersections with attachment (pp. 41-51). Hillsdale, NJ: Lawrence Erlbaum Associates.

Noldus Information Technology. (2003). Reference manual, version 5.0 for Windows edition. Netherlands: Wageningen.

Nussbaum, E. M., Elsadat, S., \& Khago, A. H. (2008). Best practices in analyzing count data: Poisson regression. In J. W. Osborne (Ed.), Best practices in quantitative methods (pp. 306-323). Thousand Oaks, CA: Sage.

Paquette, D. (2004). Theorizing the father-child relationship: Mechanisms and developmental outcomes. Human Development: 47., 193-219. http://dx.doi.org/10.1159/000078723

Power, T. G., \& Parke, R. D. (1983). Patterns of mother and father play with their 8-month-old infant: A multiple analyses approach. Infant Behavior and Development: 6., 453-459. http://dx.doi.org/10.1016/S0163-6383(83)90256-4

Robertson, J., \& Bowlby, J. (1952). Responses of young children to separation from their mothers. Courrier du Centre International de l'Enfance: 2., 131-142.

Sasaki, T., Hazen, N. L., \& Swann, W. B., Jr. (2010). The supermom trap: Do involved dads erode moms' self-competence? Personal Relationships: 17., 71-79. http://dx.doi.org/10.1111/j.1475-6811.2010.01253.x

Shaver, P. R., \& Mikulincer, M. (2007). Adult attachment strategies and the regulation of emotion. In J. J. Gross (Ed.), Handbook of emotion regulation (pp. 446-465). New York: Guilford Press.

Sroufe, L. A. (1995). Emotional development: The organization of emotional life in the early years. Cambridge, England: Cambridge University Press.

Sroufe, L. A., \& Waters, E. (1977). Attachment as an organizational construct. Child Development: 48., 1184-1199. http://dx.doi.org/10.2307/1128475

Teti, D. M., Bond, L. A., \& Gibbs, E. D. (1988). Mothers, fathers, and siblings: A comparison of play styles and their influence upon infant cognitive level. International Journal of Behavioral Development: 11., 415-432. http://dx.doi.org/10.1177/016502548801100402

Waters, E., \& Cummings, E. (2000). A secure base from which to explore close relationships. Child Development: 71., 164-172. http://dx.doi.org/10.1111/1467-8624.00130

Waters, E., \& Deane, K. (1985). Defining and assessing individual differences in attachment relationships: Q-methodology and the organization of behavior in infancy and early childhood. In I. Bretherton, \& E. Waters (Eds.), Growing points in attachment theory and research (pp. 41-65). Monographs of the Society for Research in Child Development, 50(1-2, Serial No. 209). http://dx.doi.org/10.2307/3333826

Waters, E., Wippman, J., \& Sroufe, L. A. (1979). Attachment, positive affect, and competence in the peer group: Two studies in construct validation. Child Development: 50., 821-829. http://dx.doi.org/10.2307/1128949

Weinfield, N. S., Sroufe, L. A., \& Egeland, B. (1999). The nature of individual differences in infant-caregiver attachment. In J. Cassidy, \& P. R. Shaver (Eds.), Handbook of attachment: Theory, research, and clinical applications (pp. 68-88). New York, NY: Guilford Press.

Yarrow, L. J., MacTurk, R. H., Vietze, P. M., McCarthy, M. E., Klein, R. P., \& McQuiston, S. (1984). Developmental course of parental stimulation and its relationship to mastery motivation during infancy. Developmental Psychology: 20., 492-503. http://dx.doi.org/10.1037/0012-1649.20.3.492

Yogman, M. (1981). Games fathers and mothers play with their infants. Infant Mental Health Journal: 2., 241-248. http://dx.doi.org/10.1002/1097-0355(198124)2:4<241::AID-IMHJ2280020406>3.0.CO;2-8 